\title{
Uma história da rádio pouco sonora: em torno dos arquivos sonoros radiofónicos de Portugal e Espanha ${ }^{1}$
}

\author{
Cláudia HENRIQUES ${ }^{2}$
}

\begin{abstract}
Resumo:
A construção da história da rádio depende da existência de arquivos sonoros que a expliquem a partir do seu próprio material acústico. A natureza sonora do meio exige que o seu estudo não se acomode à documentação escrita e aos testemunhos orais que, embora essenciais, são apenas uma das facetas que ajudam à construção da memória da rádio. Neste artigo, partindo de autores de referência que problematizam a dimensão sonora da rádio e a importância dos arquivos sonoros (BALSEBRE, 2002; CARLES, 1992), esperamos contribuir para uma reflexão sobre a necessidade de promoção do acesso dos investigadores ao vasto património que as rádios encerram. Fazemo-lo através do estudo de caso dos arquivos sonoros da Rádio e Televisão de Portugal e da Radio Nacional de España, com recurso à análise documental e a entrevistas em profundidade com os respetivos responsáveis. Concluímos que a dificuldade de acesso dos investigadores a estes espólios ainda subsiste, comprometendo a utilização das fontes sonoros na construção da história da mídia.
\end{abstract}

Palavras-chave: arquivos sonoros; história da rádio; Rádio e Televisão de Portugal; Radio Nacional de España.

\section{A radio history with a lot of silences: the radio sound archives of Portugal and Spain}

\begin{abstract}
:
The construction the radio's history depends on the existence of sound archives that explain it from its own acoustic material. The sound nature of the medium requires that its study does not be accommodated by written documentation and oral testimonies that, although essential, are only one of the facets that help to build the radio's memory. In this article, starting from authors who problematize the sound dimension of radio and the importance of sound archives (BALSEBRE, 2002; CARLES, 1992), we hope to contribute to a reflection on the need to promote researchers' access to the vast heritage that radios contain. We do this through the case study of the sound archives of Radio and Television of Portugal and the National Radio of Spain, using document analysis and indepth interviews with the respective responsible. We conclude that the researchers' difficulty in accessing these heritage exists, compromising the use of sound sources in the construction of the media history.
\end{abstract}

Keywords: sound archives; radio history; Radio and Television of Portugal; National Radio of Spain.

\footnotetext{
${ }^{1} \mathrm{O}$ presente artigo foi elaborado posteriormente à comunicação com o mesmo título apresentada em Santiago de Compostela, Espanha, no dia 27 de setembro de 2019, no âmbito do XVI Congreso de la Asociación de Historiadores de la Comunicación.

${ }^{2}$ Investigadora do Centro de Estudos de Comunicação e Sociedade da Universidade do Minho (CECS/UM), Portugal. Doutoranda de Estudos de Comunicação: Tecnologia, Cultura e Sociedade (Universidade do Minho, Braga, Portugal), com bolsa de doutoramento financiada pela Fundação para a Ciência e a Tecnologia (PD/BD/128176/2016).E-mail: claudia.henriques@sapo.pt
} 


\title{
Una historia de la radio con muchos silencios: en torno a los archivos sonoros de la radio de Portugal y España
}

\begin{abstract}
Resumen:
La construcción de la historia de la radio depende de la existencia de archivos sonoros que la expliquen a partir de su propio material acústico. El carácter sonoro del medio requiere que su estudio no se limite a documentación escrita y testimonios orales que, aunque imprescindibles, son sólo una de las facetas que ayudan a construir la memoria de la radio. En este artículo, a partir de autores destacados que problematizan la dimensión sonora de la radio y la importancia de los archivos sonoros (BALSEBRE, 2002; CARLES, 1992), esperamos contribuir a una reflexión sobre la necesidad de promover el acceso de los investigadores al vasto patrimonio que tienen las estaciones de radio. Lo hacemos a través del estudio de caso de los archivos sonoros de Radio y Televisión de Portugal y Radio Nacional de España, utilizando análisis documental y entrevistas en profundidad con los respectivos responsables. Concluimos que aún existe la dificultad de los investigadores para acceder a este patrimonio, comprometiendo el uso de fuentes sonoras en la construcción de la historia de los medios.
\end{abstract}

Palabras clave: archivos sonoros; historia de la radio; Radio y Televisión de Portugal; Radio Nacional de España.

\section{Introdução}

Se analisarmos bibliografia no campo da história da rádio vemos que a maior parte dos estudos se alicerça em documentação escrita, periódicos e testemunhos orais. A investigação nos arquivos históricos e hemerotecas, e a busca de informações junto de quem viveu "aqueles" tempos da rádio substituem os sons que se perderam, destruíram ou permanecem inacessíveis. A pesquisa retrospetiva da rádio vive, assim, neste paradoxo: orientada para um meio sonoro, vê-se frequentemente reduzida ao silêncio da escrita e dependente da memória.

Se o jornal, em contexto analógico, encerra em si uma ideia de finitude e perenidade, constituindo-se ele próprio como um arquivo diário, as vivências da rádio desenvolvem-se num contínuo, sem que haja um suporte fixo que as "arrume" numa edição diária que seja memória.

Investigar o som histórico significa lidar com a ausência e fragmentação dos seus registos. E significa também ultrapassar, tanto quanto possível, a sua ambiguidade e opacidade.

O interesse dos investigadores por esta temática revela-se escasso. A bibliografia disponível incide mais sobre a análise dos arquivos sonoros do ponto de vista das ciências documentais do que sobre o som enquanto objecto de investigação, imprescindível aos estudos da rádio e à construção de uma história com matizes sonoros.

Neste artigo, depois de sublinharmos as características dos sons e os desafios que se colocam aos arquivos da rádio, e de traçamos um breve enquadramento legal dos arquivos 
sonoros de Portugal e Espanha, refletimos sobre a realidade do Arquivo Sonoro da Rádio e Televisão de Portugal (RTP) e do Arquivo da Radio Nacional de España (RNE). Fazemo-lo através da análise documental e, sobretudo, das entrevistas em profundidade que fizemos aos responsáveis pelos arquivos.

Este artigo é motivado pela nossa experiência de recolha de registos sonoros, no âmbito da investigação de doutoramento em curso. A nossa tese incide sobre o processo de renovação que o jornalismo radiofónico português experimenta nas décadas de 1960 e 1970, de que o Rádio Clube Português (RCP) é o principal responsável.

O RCP foi a estação privada de referência em Portugal durante o Estado Novo (19331974), regime ditatorial liderado por Oliveira Salazar e, a partir de 1968, por Marcello Caetano (ROSAS, 1998). Juntamente com a Emissora Nacional (EN), estação oficial do regime, e a Rádio Renascença, propriedade da Igreja Católica, o RCP compõe a estrutura radiofónica fundamental, ${ }^{3}$ da década de 1930 à Revolução de 25 de Abril de 1974, que põe fim à ditadura (FERREIRA, 2001). O espólio documental do RCP, após a Revolução de 1974, e na sequência da nacionalização da rádio (PORTUGAL, 1975), ${ }^{4}$ é integrado no arquivo da atual RTP.

Para além da nossa circunstância académica, a escolha do objeto de estudo decorre de três fatores: a proximidade geográfica entre Portugal e Espanha; a realidade histórica dos dois países, semelhante ao longo do século XX; as similitudes entre a história da rádio de Portugal e Espanha; por fim, o facto de serem ambos arquivos de operadores de serviço público, conservando os mais vastos e relevantes acervos radiofónicos nacionais.

A partir da comparação entre as duas realidades, lançamos um olhar incisivo sobre um aspeto indispensável para o conhecimento e a partilha da memória da rádio: o acesso dos investigadores ao património sonoro das rádios.

\section{Os sons da rádio e os desafios da salvaguarda dos arquivos sonoros}

As características que associamos ao som - intangibilidade, invisibilidade e carácter onírico - explicam, em grande medida, a forma como a memória acústica é experienciada e

\footnotetext{
${ }^{3}$ Para um melhor enquadramento do panorama radiofónico português, da ditadura à transição para a democracia, veja-se, por exemplo, Cristo (2005) e Santos (2014, 2017).

${ }^{4}$ O Decreto-Lei n. ${ }^{\circ} 674-\mathrm{C} / 75$, de 2 de dezembro determina a nacionalização da rádio em Portugal. Só a Rádio Renascença se mantém privada.
} 
preservada. A partir de bibliografia que problematiza a dimensão sonora da rádio e dos seus registos (BALSEBRE, 2002; BUARQUE, 2008; CARLES, 1992), sublinhamos três problemas que condicionam a missão dos arquivos sonoros e concorrem para uma baixa consciência do valor patrimonial do som.

Em primeiro lugar, a essência fugaz da mensagem sonora. A palavra que a rádio emite é já passado e dela ficam resquícios na memória dos que a ouvem e em alguma imprensa da época. A mensagem radiofónica emerge como veloz e transitória, rapidamente eclipsada uma vez emitida.

A instabilidade do som e a dificuldade da sua fixação constituem um outro desafio. $\mathrm{O}$ som, para ser gravado, transmitido e acedido, necessita de dispositivos tecnológicos. Implica um conjunto de cuidados de preservação para os suportes e para os equipamentos, com a agravante da sua rápida obsolescência.

Um terceiro obstáculo diz respeito aos custos associados à conservação dos sons. As exigências de intermediação tecnológica tornam os documentos sonoros mais caros do que os escritos. Com a fita magnética, gravar e deixar para a posteridade torna-se mais fácil, mas os elevados custos conduziram a sucessivas reutilizações das fitas. Esta rotina produtiva de reaproveitamento e consequente eliminação dos registos sonoros anteriores constitui, hoje, um dos principais óbices para quem quer estudar os sons do passado.

$\mathrm{Na}$ defesa acérrima que Balsebre faz dos arquivos sonoros, é pertinente o alerta sobre a excessiva sobrevalorização do presente, e a necessidade de meios e de políticas documentais efetivas:

A rotina produtiva desta fábrica de programas diários que é uma emissora de rádio instala o culto do presente com uma servidão de tal magnitude que impede pensar no futuro, e tomar consciência de que o que não é importante hoje, daqui a dez, vinte ou trinta anos pode ser muito importante. [...] Somente o zelo pessoal de alguns indivíduos permitiu que décadas depois fosse possível recuperar, às vezes escondidas em armários pessoais, gravações que são o único testemunho sólido de um período ou de uma época (BALSEBRE, 2002, p. 47). 


\section{A memória sonora da rádio em Portugal e Espanha: marcos e vazios legais}

Em Portugal, os arquivos da rádio não têm um enquadramento legal específico. No entanto, alguns documentos legais constituem bases importantes para a discussão da preservação e do acesso a este tipo de arquivos.

A lei da rádio (PORTUGAL, 2010) define um prazo mínimo de 30 dias para a conservação das emissões radiofónicas. Esta determinação não está tanto relacionada com a defesa patrimonial do espólio sonoro da rádio, mas com o direito de resposta que aos cidadãos assiste e com a defesa dos direitos de autor.

A lei tem o mérito de definir responsabilidades acrescidas para a concessionária de serviço público, entre as quais "manter e actualizar os arquivos sonoros" (PORTUGAL, 2010). E, numa perspetiva global, defende que as estações "de âmbito nacional e regional devem organizar arquivos sonoros e musicais com o objectivo de conservação dos registos de interesse público" (PORTUGAL, 2010). O documento prevê ainda a existência de "uma portaria conjunta dos membros do Governo responsáveis pela cultura e pela comunicação social”, capaz de regular a utilização destes registos, tendo em conta "o seu valor histórico, educacional e cultural" (PORTUGAL, 2010). Esta portaria, porém, nunca se concretizou.

O Contrato de Concessão de Serviço Público de Rádio e Televisão (2015, p. 26$)^{5}$ deixa claro que é dever da concessionária "manter em arquivo [...] os registos sonoros e audiovisuais que [...] possuam valor histórico, sociológico, científico, educativo ou artístico". Para além de garantir a existência de um arquivo sonoro, conservado para lá dos prazos legais, este contrato prevê a consulta externa dos documentos. Porém, o contrato de concessão tem lacunas ou “direções" que menorizam o valor patrimonial do arquivo. Por exemplo, não é especificada a estrutura, em termos de recursos técnicos e humanos, que deverá estar adstrita a este serviço. Por outro lado, a leitura do articulado mostra que há um foco muito claro na questão financeira e dos direitos de autor, que retira protagonismo à valorização do património sonoro per se.

Ao contrário de França, em que o Institut National de l'Audiovisuel (INA), fundado em 1975, recebe o depósito legal das produções de rádio e televisão, em Portugal (tal como em Espanha) não existe um organismo que se ocupe da gestão do património sonoro nacional. Nos últimos anos, em Portugal, a discussão em torno da criação de um Arquivo Sonoro Nacional 
(ASN) tem sido recorrente, gerando expectativas de definição de uma política para os arquivos sonoros (NUNES, 2011).

Em 2006, a então ministra da Cultura anuncia a criação do ASN (PROJETO..., 2018), que funcionaria como depósito legal dos fonogramas, em cumprimento da lei em vigor desde 1982 (PORTUGAL, 1982. Ao longo dos anos, vários diplomas legais foram produzidos no sentido de proteger os documentos sonoros e de criar um ASN. ${ }^{6}$ No entanto, só em 2019 é formada uma equipa de instalação (PORTUGAL, 2019).

Importa perceber que tipo de documentação sonora é enquadrada pelo futuro ASN. Em janeiro de 2019, quando anunciou a equipa de instalação do ASN, a ministra da Cultura sublinhou: "O património musical é uma área a que queremos dar grande impulso este ano e nos próximos anos" (MINISTRA..., 2019). Antes, em 2013, o Partido Comunista Português (PCP) propõe a criação de um ASN que proceda à "salvaguarda do património imaterial constituído pela sonoridade - a música, as várias expressões musicais, os instrumentos, a produção musical, artística, cultural, folclórica" (PCP..., 2013). O PCP defende também que o ASN seja "um instituto público, mas integrado num outro, por exemplo, no Museu da Música" (PCP..., 2013). Declarações como estas apontam para um ASN estruturalmente pensado para o património musical.

Em setembro de 2019, a equipa de instalação do ASN dá a conhecer o seu programa e lança um inquérito nacional, por forma a inventariar instituições com espólios sonoros relevantes. O programa de ação é lato no entendimento que faz dos documentos sonoros abrangidos:

O som de um pássaro, de um vulcão, de uma rua ou de um bosque, uma entrevista, uma reportagem, um disco de um intérprete celebrado, uma gravação esquecida que não foi incluída no disco comercial com milhões de cópias vendidas, uma notícia transmitida que relata um evento aparentemente banal, mas que virá a revelar-se determinante na história de um país... Todos constituem o património sonoro nacional (EQUIPA INSTALADORA, c2019).

\footnotetext{
${ }^{6}$ Referimo-nos, nomeadamente, à Resolução da Assembleia da República n. ${ }^{\circ}$ 150/2013, de 25 de outubro, ao Despacho n. ${ }^{\circ}$ 1164-A/2014, de 22 de janeiro, e à Resolução da Assembleia da República n. ${ }^{\circ}$ 79/2018, de 26 de março.
} 
No caso de Espanha, também não existem leis específicas para os arquivos sonoros. A lei geral do audiovisual determina que "os operadores de comunicação audiovisual serão obrigados a preservar e a conservar o arquivo de imagens em movimento e áudio" (ESPANHA, 2010. A lei da rádio e televisão públicas indica que a RTVE (Corporación de Radio y Televisión Española) deve "garantir a preservação de arquivos históricos audiovisuais" (ESPANHA, 2006). Ainda que estas leis considerem este tipo de arquivos e as obrigações que recaem sobre a empresa pública audiovisual, ficam-se por indicações gerais. Nem estes diplomas mencionam como se deverá processar, e com que meios, a salvaguarda do património audiovisual, nem um diploma específico foi criado para enquadrar o espólio sonoro da rádio.

Os vazios legislativos e políticos em que o património sonoro navega, colocam-no, uma vez findos os curtos prazos legais de conservação, à mercê dos objetivos e vontades das instituições e empresas.

\section{Metodologia}

Em seguida, contrastamos a realidade do Arquivo Sonoro da RTP com a do Arquivo da RNE. Partimos da leitura de bibliografia contextualizadora do objeto de estudo que, no caso português, é particularmente escassa. Nesta investigação, de matriz qualitativa, recorremos à análise documental (BOWEN, 2009) de materiais impressos de divulgação dos serviços de arquivo, bem como da informação disponível nos sites das concessionárias de serviço público audiovisual.

Mas, a principal fonte de informação foram os responsáveis por estes arquivos, Paloma Carrere (RNE) e Eduardo Leite (RTP), a quem fizemos entrevistas semiestruturadas nos dias 10 de maio e 4 de junho de 2019, em Madrid (Espanha) e em Lisboa (Portugal). Estas entrevistas permitem uma relação dinâmica com os entrevistados. Como não são processos de sentido único como as entrevistas estruturadas, as questões, na sua maioria abertas, suscitam respostas com profundidade (CROUCHER; CRONN-MILLS; QUIVY; CAMPENHOUDT, 1998). As questões colocadas centraram-se em três eixos de análise: a constituição e história do arquivo, a equipa e o tratamento técnico desenvolvido, e o acesso dos utilizadores aos acervos destas estações de rádio. 


\section{Arquivo Sonoro da RTP}

\section{História e constituição}

O Arquivo Sonoro da RTP tem a sua origem na criação, em 1935, da EN, estação oficial do regime salazarista. A música emitida em direto e a música gravada têm um importante papel na programação da emissora. Logo no primeiro organograma da EN consta uma área orgânica designada "Arquivo Musical e Discoteca". Enquanto o Arquivo Musical tinha a seu cargo as partituras para uso das orquestras da EN, a Discoteca geria a música gravada. $\mathrm{O}$ atual arquivo da RTP está intimamente ligado à fundação dessa Discoteca (LEITE, 2014).

$\mathrm{O}$ acervo deste arquivo confunde-se com a história e evolução da rádio pública. $\mathrm{O}$ documento mais antigo de produção própria data de 1936. Para além dos conteúdos da EN e, a partir de 1976, da Radiodifusão Portuguesa (RDP), sua sucessora, o arquivo é constituído pela produção sonora de fundos documentais como os do RCP e dos Emissores Associados de Lisboa. $^{7}$

$\mathrm{Na}$ atualidade, o Arquivo Sonoro gere a documentação produzida pelas várias estações da rádio pública e pelas delegações locais, integradas, desde 2004, na empresa pública Rádio e Televisão de Portugal (RTP).

\section{Equipa e tratamento técnico}

O Arquivo Sonoro da RTP conta com uma equipa de nove pessoas, incluindo o coordenador, das quais três têm formação em Ciências Documentais. As tarefas de tratamento documental seguem as normas arquivísticas internacionais e distribuem-se por duas áreas principais: a dimensão fonográfica e o arquivo histórico. Ao arquivo compete o tratamento de toda a documentação sonora produzida e emitida pela rádio pública atualmente, assim como da documentação histórica à sua guarda.

Arquivar é sempre um ato de escolha, fundado em critérios e práticas mais ou menos definidas. Implica gerir uma massa de documentos que não têm o mesmo valor e que não podem

\footnotetext{
${ }^{7}$ Os Emissores Associados de Lisboa eram um conjunto de pequenas estações agrupadas em Lisboa, bastante populares, sobretudo nas décadas de 1950 e 1960 (SANTOS, 2014).
} 
ser guardados na totalidade. Desconhecem-se os critérios de seleção utilizados no passado. Eduardo Leite explica: "Sabemos que o que era gravado era relativamente pouco e segmentado. Não se gravavam indicativos, noticiários, sequências de programas, ou publicidade, que dessem uma ideia de continuidade e de completude da emissão"8.

O aparecimento da fita magnética no final da década de 1940 vai ser determinante para o incremento das gravações e do arquivo. No entanto, os custos, o espaço ocupado e o caráter reutilizável vão comprometer muitas das gravações feitas.

Depois da Revolução de Abril de 1974, as bobines de circulação são copiadas para arquivo. Mas só em 2009 surge um documento que, não sendo uma política do arquivo, define "A prática de avaliação e seleção de documentos no arquivo da rádio" (FERREIRA, 2013, p. 12). ${ }^{9}$ Historicamente, o que era conservado em arquivo definitivo eram programas de música erudita, programas por amostragem, reportagens, e programas sobre atos oficiais. A partir de 2009, registam-se mudanças. É introduzido um sistema de gravação contínua das emissões que, se na sua origem visava garantir a obrigação legal de preservação das emissões, acabou também por trazer dividendos para os serviços de arquivo.

A manutenção destas gravações contínuas dá algumas garantias de preservação para memória futura, mas também coloca interrogações. Estas emissões integrais não são tratadas arquivisticamente, o que significa que não existem possibilidades de pesquisa para além da designação da emissora, e data e hora em que determinado conteúdo foi transmitido. No entanto, é também a partir de 2009 que é adotado um novo sistema de produção de rádio. O arquivo passa a aceder diretamente aos conteúdos emitidos e a guardar lotes de programas, permitindo uma continuidade de conteúdos em arquivo, até então inédita.

Para os chamados "brutos" - a totalidade de determinado material sonoro gravado, sem edição - não existe uma política de salvaguarda sistemática. Na prática, a estação de música clássica, a Antena 2, é a única que tem o cuidado de enviar os "brutos" dos concertos de música para o arquivo.

\footnotetext{
${ }^{8}$ Entrevista dada por Eduardo Leite à autora, no dia 4 de junho de 2019, em Lisboa.

9 Trata-se de um documento interno, ao qual não tivemos acesso.
} 
No contexto da rápida deterioração dos documentos originais, e do desenvolvimento das tecnologias digitais, a solução da RTP para a preservação a longo prazo reside na digitalização do acervo.

\section{Acesso e comunicação}

O Arquivo da RTP serve de apoio aos utilizadores internos, mas também é procurado por investigadores, outros meios de comunicação, e produtores de cinema e documentários.

O projeto PAR - Portal Arquivo RTP: A nossa memória coletiva à distância de um click, financiado por fundos da União Europeia entre 2015 e 2017, é a face mais recente da abertura do arquivo à sociedade civil. Disponibiliza online, gratuitamente, milhares de documentos, e é alimentado em permanência. Em março de 2019, quando foi lançada a APP RTP Arquivos, contava com 42.000 conteúdos de áudios, textos, fotografias e vídeos (RTP..., 2019).

No entanto, este portal não disponibiliza a totalidade do acervo. A colocação de documentos na plataforma exige um processo de seleção documental e um trabalho técnico prévio. Os critérios de escolha e a priorização de uns documentos em relação a outros deixam de fora uma parte considerável do acervo. Por outro lado, apesar de, em teoria, o projeto “facilitar o acesso público e universal ao património audiovisual da rádio e televisão portuguesa" (FICHA..., 2018), na prática, como atesta Eduardo Leite, são ainda poucos os registos sonoros disponibilizados online. O que se verifica é que o sistema informático que gere a documentação da televisão está preparado para a publicação direta de conteúdos, cumprindo os desafios desenhados pelo portal, ao passo que o sistema de gestão documental da rádio requer mais operações manuais.

Além da documentação disponibilizada no PAR, os utilizadores podem aceder à documentação em depósito. Para tal, fazem o pedido via e-mail, telefone ou através do portal. Os pedidos são recebidos pela área de Acesso Externo ao Arquivo, que solicita aos serviços técnicos do Arquivo a pesquisa.

Uma vez feito o levantamento pelos técnicos de arquivo, a área de Acesso Externo comunica ao utilizador os resultados da pesquisa, tendo em vista a venda dos registos sonoros. É possível, por marcação, consultar os registos nas instalações do arquivo, mas, conforme contacto com a responsável pela área de Acesso Externo, a consulta local por investigadores é 
considerada "uma exceção". A consulta local, com preço fixado em tabela, está apenas definida para os utilizadores de natureza comercial. ${ }^{10}$

O fornecimento de cópias dos conteúdos está sujeito a uma tabela de preços (TABELA..., 2019), que distingue a utilização para fins comerciais da utilização para fins não comerciais, mas que ainda assim é onerosa para o utilizador. $^{11}$

Em toda esta dinâmica, há duas instâncias de intermediação: primeiro, a área de Acesso Externo ao Arquivo, que é o pivot de todo o processo; depois, os técnicos de arquivo que fazem a pesquisa pelo utilizador. O utilizador externo não tem qualquer acesso aos instrumentos de pesquisa do Arquivo.

\section{O Arquivo da RNE}

\section{História e constituição}

A criação do Arquivo da RNE é indissociável da história de Espanha. A RNE nasce em 1937, em plena Guerra Civil. A emissora rapidamente se torna instrumento e veículo oficial do regime ditatorial do General Franco, que se prolongaria até 1975 (FAUS BELAU, 2008).

Apesar do esforço de salvaguarda levado a cabo pelos funcionários, durante décadas a documentação esteve guardada num pequeno depósito, sem critérios de gestão arquivística. Só em 1973, com a construção do edifício da Casa da Rádio (Madrid), o arquivo ganha espaço, estrutura e quadro de pessoal adequados às suas funções.

O Arquivo Sonoro da RNE tem um duplo objetivo. Por um lado, servir de apoio à elaboração de programas dos canais da RNE e de toda a RTVE. Por outro, custodiar e legar um arquivo histórico sonoro de valor indiscutível.

O registo mais antigo de produção própria que o Arquivo da RNE conserva data de 1947. Mas o acervo do arquivo integra sons anteriores, alguns dos quais prévios ao nascimento da rádio. Apesar de deter outros fundos documentais, este arquivo é composto, na sua maioria, pela documentação produzida pelas seis emissoras da rádio pública.

\footnotetext{
${ }^{10}$ Conversa telefónica com Filomena Fernandes, responsável pela área de Acesso Externo ao Arquivo da RTP, no dia 22 de julho de 2019.

${ }^{11}$ Para fins não comerciais, designadamente relacionados com a investigação, os preços variam, pela tabela em vigor desde 15 de março de 2019 , entre $8 €$ (até 15 minutos), $15 €$ (de 15 a 45 minutos) e $25 €$ (mais de 45 minutos), a que acresce o IVA à taxa legal em vigor.
} 
O espólio do Arquivo inclui a documentação escrita utilizada no decurso da atividade radiofónica, mas o principal destaque vai para a documentação sonora. Os fundos sonoros estão classificados em dois grandes grupos: musicais e não musicais. Os musicais são compostos pelos registos gravados de música clássica, tradicional e ligeira. Para além dos fonogramas comerciais, incluem inúmeras gravações em direto realizadas pela RNE de concertos, ciclos de música ou festivais. Em pé de igualdade com a música, o Arquivo da RNE dá grande relevo à guarda e tratamento de fundos não musicais, onde se incluem os arquivos de palavra, dramáticos e de efeitos (ARIZA CHICHARRO, 2004).

\section{Equipa e tratamento técnico}

A equipa do Arquivo da RNE é composta por 29 técnicos, maioritariamente com formação em Ciências Documentais.

Em 1998, a RNE iniciou um projeto de digitalização massiva do seu espólio que durou quatro anos (GRAU MORACHO; GUALLAR DELGADO, 2003). Foi um investimento custeado na totalidade pela RTVE, e levado a cabo por arquivistas, informáticos e engenheiros de som internos, e por profissionais da IBM, especialistas em operações de digitalização e engenharia de sistemas. Com a digitalização de 190.000 horas, o Arquivo da RNE deu um passo importante para a preservação do seu património, criou nos utilizadores internos uma nova cultura de pesquisa e acesso ao arquivo por meio da intranet, e alterou o processo de incorporação de novos documentos (CRESPO OCAÑA; GÓMEZ CORNEJO; RODEÑO ARRÁEZ, 2003).

Desde 2011 que a RNE partilha com os centros de produção da RTVE o sistema de gestão de arquivo ARCA (MARTA LAZO; ORTIZ SOBRINO, 2013). Os fundos documentais estão estruturados tendo em conta o seu tipo (texto, fotografia, áudio e vídeo), e localizados em treze bases de dados. Este sistema constitui-se como uma plataforma para onde convergem todas as fontes documentais necessárias aos utilizadores.

Os níveis de procura do património documental da RNE aumentaram consideravelmente. Os profissionais da rádio pública já não estão tão dependentes dos documentalistas. Eles próprios tornam-se agentes do processo de pesquisa e de seleção de 
conteúdos fomentado pelo sistema. Por outro lado, embora independentes, o sistema documental dialoga com o sistema de produção radiofónica, podendo receber dele conteúdos.

Na procura de um sistema o mais integrado possível, os arquivistas tentam sensibilizar os profissionais para a entrega de "brutos" e da documentação de suporte ao som produzida. A preservação dos "brutos" é importante para o Arquivo. Trata-se de um material que pode ser reutilizado posteriormente, para além de ter um valor histórico que não pode ser descurado numa entidade pública como a RNE. Mas, como refere Paloma Carrere, essa tarefa é muito difícil, "sobretudo no caso dos jornalistas, dado o ritmo voraz em que trabalham". Tal como no caso da RTP, a área da música clássica é a que melhor responde a este tipo de solicitações ${ }^{12}$.

A estratégia de conservação a longo prazo passa pela gravação e digitalização das 24 horas de emissão de todos os canais da rádio estatal, embora, como salienta Carrere, não haja tempo nem recursos para tratar as gravações diárias que se vão acumulando.

A seleção documental praticada no Arquivo da RNE tem em conta razões históricas, para lá do interesse informativo da documentação. Os critérios seguidos pela RNE na definição das gravações que se destinam ao arquivo definitivo são, em relação à RTP, mais claros e transparentes. Numa lista vasta (ARIZA CHICHARRO, 2004), destacam-se: os documentos relativos aos mais altos representantes do Estado; os que possuam importância histórica nacional ou internacional; as vozes de pessoas destacadas do mundo da política, das artes, da ciência e do desporto; os programas, reportagens e crónicas sobre acontecimentos de relevo; os quatro programas informativos, ou diários falados, emitidos pela Radio 1, e os concertos de música clássica produzidos pela RNE.

\section{Acesso e comunicação}

O acesso aos fundos documentais da RNE está reservado ao pessoal da RTVE, mas, mediante pedido prévio, a consulta é aberta a investigadores.

Deferido o pedido, é feita a marcação da consulta, consoante as disponibilidades dos funcionários e dos postos de escuta. Nas instalações do arquivo, o investigador é acolhido, recebe folhetos explicativos do funcionamento dos serviços de arquivo, e tem acesso aos instrumentos de referência por meio da intranet corporativa. Para além de poder fazer pesquisas,

\footnotetext{
${ }^{12}$ Entrevista dada por Paloma Carrere à autora, no dia 10 de maio de 2019, em Madrid.
} 
com ou sem apoio dos documentalistas, o investigador tem acesso directo, via intranet, aos documentos sonoros e escritos que pretende consultar. Os investigadores têm à sua disposição uma sala de leitura, dotada de vários postos de consulta, visualização, impressão, audição, descarga e edição dos fundos documentais.

Ao contrário do que sucede na RTP, a RNE não cede cópias do acervo documental a investigadores. As cópias só são vendidas para fins comerciais, a preços incomportáveis para um investigador.

\section{Discussão e conclusões}

Neste artigo trouxemos para o centro do debate a situação atual dos arquivos sonoros da RTP e da RNE, que, mais do que arquivos de empresas públicas, são os repositórios principais da memória sonora de Portugal e Espanha.

O enquadramento legal em matéria de arquivos sonoro surge mais robusto em Portugal do que em Espanha. No entanto, a abordagem que Espanha faz em relação a este património é mais estruturada do que a experiência portuguesa analisada.

Em Portugal, a criação de um ASN pode constituir uma oportunidade para repensar as especificidades, o valor e a extensão deste património. Mas, para tal, não pode existir, como algumas linhas de discurso oficiais sugerem, uma identidade unívoca, deliberada ou não, entre património sonoro e património musical. Isso seria reduzir e empobrecer o próprio universo sonoro. Seria excluir ou relegar para segundo plano os arquivos não musicais da rádio, onde se incluem, por exemplo, noticiários, entrevistas, declarações ou reportagens com valor histórico.

Um dos aspetos em que o modelo do arquivo da RNE se destaca é na forma integrada como olha para o seu património. A divisão entre fundos musicais e não musicais é, mais do que um modo de organizar e gerir o espólio, uma forma de enunciar que o património da rádio vive, simultaneamente, de música, de palavra, de efeitos e de silêncios (BALSEBRE, 2012). De igual modo, se em Portugal a documentação escrita não está sob a alçada direta do Arquivo Sonoro da RTP, em Espanha os documentos escritos e os sons são parte constituinte do Arquivo da RNE, completando-se mutuamente.

A experiência de consulta dos documentos sonoros também é diferente em ambos os arquivos. No Arquivo da RTP, os serviços não estão orientados para a consulta prévia no local, 
mas sim para a comercialização de cópias dos materiais de arquivo. No Arquivo da RNE, pelo contrário, as instalações, consideravelmente maiores do que as do arquivo português, estão preparadas para a consulta externa. A ida à Casa da Rádio, em Madrid, é a única forma que o utilizador tem de aceder aos documentos. No caso da RTP, a compra de registos, de preferência sem consulta prévia, é o modus operandi. As práticas de cada um dos arquivos - consulta local (RNE) versus acesso a cópias do arquivo sonoro (RTP) - beneficiariam mais os utilizadores e a missão de serviço público das concessionárias, se não se excluíssem mutuamente.

$\mathrm{Na}$ explicação do contraste entre Portugal e Espanha é importante destacar a diferente mobilização de meios técnicos e humanos, com desvantagem para o Arquivo RTP. Uma equipa de trabalho com três vezes mais profissionais, e com maior formação especializada na área, como no caso espanhol, permite, seguramente, atingir resultados mais sólidos.

A aposta da RTP na colocação online dos conteúdos dos arquivos é um passo importante para a desmaterialização e democratização dos arquivos. Porém, não resolve todos os problemas de acesso à memória sonora e, muito menos, é a solução acabada para as demandas dos investigadores. O portal RTP Arquivos revela-se ainda muito centrado na imagem, sendo os conteúdos sonoros uma parte ínfima do que já foi disponibilizado. As necessidades dos investigadores nem sempre coincidem com os critérios da instituição que disponibiliza o património sonoro. O caso enunciado pelo historiador da rádio Hugh Chignell (2013) é bem elucidativo do desencontro entre investigadores e instituições de arquivo. Chignell fez uma listagem dos programas históricos da $\mathrm{BBC}$ que considera mais significativos, e chega à conclusão que nenhum deles está disponível online. "Eles podem ser partes extremamente importantes da nossa herança da rádio, mas não aos olhos dos arquivos da $\mathrm{BBC}$ ", lamenta Chignell (2013).

A legislação nacional sobre os arquivos sonoros, sendo importante para as boas práticas nesta matéria, não é, por si só, garantia da valorização da memória sonora. Pode ser um pronto de partida para a defesa do património sonoro, mas só será produtiva se as instituições detentoras deste património se abrirem verdadeiramente à sociedade. Se os arquivos forem disponibilizados ao público em geral e pesquisáveis sem necessidade de mediação obrigatória. Se os arquivos tiverem recursos humanos especializados e em número suficiente. Se existirem condições de acolhimento que permitam ao utilizador ouvir os sons num espaço que lhe seja 
reservado. Se, ouvidos os sons, for possível obter a reprodução dos documentos a um custo controlado e adequado aos fins de investigação. Se utilizadores, arquivistas e instituições detentoras de património sonoro não se evitarem. Se, juntos, discutirem necessidades e ensaiarem políticas e estratégias que, questionando o império da escrita e da imagem, façam da memória sonora um território de escuta e vivência inadiáveis.

\section{Referências}

ARIZA CHICHARRO, Rosa María. El archivo de la palabra de Radio Nacional de España. Revista General de Información y Documentación, Madrid, v. 14, n. 2, p. 29-58, 2004. Disponível em: https://revistas.ucm.es/index.php/RGID/article/view/RGID0404220029A. Acesso em: 10 dez. 2019.

BALSEBRE, Armand. Per una defensa dels arxius sonors de la nostra memoria. Item, Barcelona, n. 32, p. 45-50, 2002.Disponível em: https://raco.cat/index.php/Item/article/view/22581. Acesso em:10 dez. 2019.

BALSEBRE, Armand. El lenguaje radiofónico. Madrid: Cátedra, 2012.

BOWEN, Glenn A. Document analysis as a qualitative research method. Qualitative Research Journal, v. 9, n. 2, p. 27-40, 2009.Disponível em: https://doi.org/10.3316/QRJ0902027. Acesso em:10 dez. 2019.

BUARQUE, Marco Dreer. Documentos sonoros: características e estratégias de preservação. Pontodeacesso, Salvador, v. 2, n. 2, p. 37-50, 2008. Disponível em: http://dx.doi.org/10.9771/1981-6766rpa.v2i2.3021. Acesso em: 10 dez. 2019.

CARLES, José Luis. Nuestra memoria sonora: Importancia de los archivos sonoros. Historia y Fuente Oral, Barcelona, n. 7, p. 189-191, 1992.Disponível em: www.jstor.org/stable/27753359. Accessed 7 July 2021. Acesso em: 10 dez. 2019.

CONTRATO DE CONCESSÃO DE Nuestra memoria sonora: importancia de los archivos sonoros. Historia y Fuente Oral, Barcelona, n. 7, p. 189-191, 1992.Disponível em: www.jstor.org/stable/27753359. Accessed 7 July 2021. Acesso em: 10 dez. 2019.

CHIGNELL, Hugh. The BBC, radio archives and the role of the academic researcher, 2013. Disponível https://www.academia.edu/11178941/The_BBC_radio_archives_and_the_role_of_the_acade mic_researcher. Acesso em: 10 dez. 2019. 
SERVIÇO PÚBLICO DE RÁDIO E TELEVISÃO, entre o Estado Português e a Rádio e Televisão de Portugal. 6 mar. 2015. Disponível em: http://media.rtp.pt/empresa/informacao/contrato-de-concessao-publica-radio-etelevisao/. Acesso em: 10 dez. 2019.

CRESPO OCAÑA, Ángel.; GÓMEZ-CORNEJO ORTIZ, Juan C.; RODEÑO ARRÁEZ, Miguel J. The Radio Nacional de España sound archive preservation. In: ELPUB, INTERNATIONAL CONFERENCE ON ELECTRONIC PUBLISHING, 7., 2003. Proceedings. Guimarães: Universidade do Minho, 2003, p. 125-132. Disponível em: https://elpub.architexturez.net/system/files/pdf/0319.content.07509_0.pdf. Acesso em: 10 dez. 2019.

CRISTO, Dina. A rádio em Portugal e o declínio do regime de Salazar e Caetano (19581974). Coimbra: MinervaCoimbra, 2005.

CROUCHER, Stephen M.; CRONN-MILLS, Daniel. Understanding communication research methods. London: Routledge, 2015.

EQUIPA INSTALADORA. Arquivo Nacional do Som, c2019. Página inicial. Disponível em: http://arquivonacionaldosom.gov.pt/. Acesso em: 10 dez. 2019.

ESPANHA. Ley 17/2006, de 5 de junio. De la radio y la televisión de titularidad estatal. Disponível em: https://www.boe.es/eli/es/1/2006/06/05/17/con. Acesso em: 10 dez. 2019.

ESPANHA. Ley 7/2010, de 31 de marzo. General de la Comunicación Audiovisual. Disponível em: https://www.boe.es/eli/es/1/2010/03/31/7/con. Acesso em: 10 dez. 2019.

FAUS BELAU, Ángel. La radio en España (1896-1977). Una historia documental. Madrid: Taurus, 2008.

FERREIRA, José Medeiros (Ed.). Portugal em transe (1974-1985). Lisboa: Estampa, 2001.

FERREIRA, Sónia Paula Marçal. O arquivo da rádio da RTP: preservação do seu acervo. 2013. Dissertação (Mestrado em Ciências da Informação e Documentação) - NOVA FCSH, Lisboa, 2013.2 Disponível em: https://run.unl.pt/bitstream/10362/12236/1/Dissertacao_SoniaFerreira.pdf. Acesso em: 10 dez. 2019.

FICHA de projeto. RTP Arquivos, 2018. Disponível em: https://arquivos.rtp.pt/ficha-deprojeto/. Acesso em: $10 \mathrm{dez} .2019$.

GRAU MORACHO, Jordi; GUALLAR DELGADO, Javier. RNE digitaliza su archivo sonoro. EI Profesional de la Información, Barcelona, v. 12, n. 2, p. 130-132, 2003.Disponível em: http://profesionaldelainformacion.com/contenidos/2003/marzo/12.pdf. Acesso em: $10 \mathrm{dez}$. 2019. 
LEITE, Eduardo. 76 anos de gravação sonora na rádio pública: o desafio da permanência. In: SILVA, Manuel Deniz; PESTANA, Maria do Rosário (Ed.). Indústria da música e arquivos sonoros em Portugal no século XX: práticas, contextos, patrimónios. Cascais: CMC/ INET, 2014. p. 139-143.

MARTA-LAZO, Carmen; ORTIZ SOBRINO, Miguel-Ángel. Gestión de los fondos documentales en Radio Nacional de España. El Profesional de la Información, Barcelona, v. 22, n. 5, p. 399-403, 2013.Disponível em: https://doi.org/10.3145/epi.2013.sep.04. Acesso em: 10 dez. 2019.

MINISTRA da Cultura cria equipa para tratar do Arquivo Sonoro Nacional. Diário de Notícias, 31 jan. 2019. Disponível em: https://www.dn.pt/lusa/interior/ministra-da-cultura-cria-equipapara-tratar-do-arquivo-sonoro-nacional--10518427.html. Acesso em: 10 dez. 2019.

NUNES, António Manuel. Arquivos sonoros: realidade proto-emergente em Portugal?. Estudos do Século XX, Coimbra, n. 11, p. 53-68, 2011.Disponível em: http://dx.doi.org/10.14195/1647-8622_11_4. Acesso em: 10 dez. 2019.

PCP apresenta Projecto de Lei para a criação do Arquivo Sonoro Nacional. PCP - Partido Comunista Português, 2013. Disponível em: https://www.pcp.pt/pcp-apresenta-projecto-delei-para-cria\%c3\%a7\%c3\%a3o-do-arquivo-sonoro-nacional. Acesso em: 10 dez. 2019.

PORTUGAL. Decreto-Lei n. ${ }^{\mathbf{0}}$ 674-C/75, de 2 de dezembro. Nacionaliza as posições sociais no capital de várias sociedades que no território continental exercem a actividade de radiodifusão. Disponível em: https://dre.pt/application/conteudo/302484. Acesso em: 10 dez. 2019.

PORTUGAL. Decreto-Lei n. ${ }^{\mathbf{7}}$ 74/82, de 3 de março. Regulamenta o depósito legal. Disponível em: https://dre.pt/home/-/dre/599921/details/maximized. Acesso em: 10 dez. 2019.

PORTUGAL. Lei n. ${ }^{\circ}$ 54/2010, de 24 de dezembro. Aprova a Lei da Rádio, revogando a Lei n. ${ }^{\circ}$ 4/2001, de 23 de fevereiro. Disponível em: https://dre.pt/pesquisa//search/306576/details/maximized. Acesso em: 10 dez. 2019.

PORTUGAL. Resolução da Assembleia da República n. ${ }^{\circ}$ 150/2013, de 25 de outubro. Recomenda ao Governo a proteção dos documentos sonoros que sejam parte do património cultural português. Disponível em: https://dre.pt/home/-/dre/504155/details/maximized. Acesso em: 10 dez. 2019.

PORTUGAL. Despacho n. ${ }^{\circ}$ 1164-A/2014, de 22 de janeiro. Determina a criação de uma equipa de preparação do Arquivo Sonoro Nacional. Disponível em: https://dre.pt/home//dre/3246439/details/maximized. Acesso em: 10 dez. 2019. 
PORTUGAL. Resolução da Assembleia da República n. ${ }^{0}$ 79/2018, de 26 de março. Recomenda ao Governo a criação de um Arquivo Sonoro Nacional. Disponível em: https://dre.pt/home/-/dre/114913730/details/maximized. Acesso em: 10 dez. 2019.

PORTUGAL. Resolução do Conselho de Ministros n..$^{\circ}$ 36/2019, de 18 de fevereiro. Cria a equipa de instalação do Arquivo Nacional do Som. Disponível em: https://dre.pt/home//dre/119674803/details/maximized. Acesso em: 10 dez. 2019.

PROJETO do Arquivo Sonoro Nacional soma 12 anos de espera. TSF Rádio Notícias, 8 fev. 2018. Disponível em: https://www.tsf.pt/lusa/projeto-do-arquivo-sonoro-nacional-soma-12anos-de-espera-9105701.html. Acesso em: 10 dez. 2019.

QUIVY, Raymond; CAMPENHOUDT, Luc Van. Manual de investigação em ciências sociais. Lisboa: Gradiva, 1998.

ROSAS, Fernando (Ed). O Estado Novo (1926-1974). Lisboa: Estampa, 1998.

RTP Arquivos já tem app dedicada. RTP, 8 mar. 2019. Disponível em: http://media.rtp.pt/extra/noticias/rtp-arquivos-ja-app-dedicada/. Acesso em: 10 dez. 2019.

SANTOS, Rogério. A rádio em Portugal. "Sempre no Ar, Sempre Consigo" (1941-1968). Lisboa: Colibri, 2014.

SANTOS, Rogério. A Emissora Nacional e as mudanças políticas (1968-1975). Coimbra: MinervaCoimbra, 2017.

TABELA de preços. RTP Arquivos, 2019. Disponível em: https://arquivos.rtp.pt/tabela-deprecos/. Acesso em: $10 \mathrm{dez} .2019$.

Submetido em: 11.12.2019.

Aprovado em: 23.12.2020. 